\title{
DEVO, NÃO NEGO: $O$ DIREITO FINANCEIRO E O DILEMA DA DÍVIDA PÚBLICA
}

Coluna publicada em 17.10.2017: <https://www.conjur.com.br/2017-out-17/ contas-vista-devo-nao-nego-direito-financeiro-dilema-divida-publica $>$

Após mais de duas décadas de dedicação ao Direito Financeiro continuo a descobrir que ainda há muito a ser estudado. E a importância dos temas não permite compreender como podem ser deixados de lado, até ignorados, pelos juristas. É certo que mais recentemente se veem louváveis avanços, mas a cada dia surgem novas questôes, que se unem às antigas, para compor esse quadro de um ramo do Direito marcado por um vazio doutrinário imenso a ser preenchido.

Mas quem se interessa pelo Direito Financeiro deve ver estas lacunas como um desafio instigante a ser enfrentado. Poucos ramos do Direito precisam tanto de estudiosos que queiram efetivamente contribuir com pesquisas sobre assuntos realmente relevantes, e que precisam ser mais explorados.

Como se pode conceber, por exemplo, estar o País está à beira de uma profunda reforma da previdência social e o orçamento da seguridade social ser um verdadeiro "deserto doutrinário"? Poucos textos, muita controvérsia, só sobram dúvidas e incertezas. Afinal, existe ou não o déficit da previdência? E nessas condições a reforma avança. Pouco provável que possa dar bom resultado.

As condições econômicas pioram, o dinheiro fica curto, não há mais como aumentar a carga tributária, que já passou do limite suportável, e no lado do gasto público o dinheiro é desperdiçado por falta de planejamento, má gestão, baixa qualidade do gasto. As normas de planejamento e orçamento não são levadas a sério, os aperfeiçoamentos na legislação orçamentária dormem nas gavetas do Congresso há décadas. E os estudos sobre esses temas mostram-se ainda incipientes.

A participação do poder público no financiamento da infraestrutura é outro aspecto cujo estudo precisa ser aprofundado, a fim de compatibilizar com o plane- 
jamento de longo prazo e nossa organização federativa, sendo fundamental para o desenvolvimento do país. ${ }^{1}$

O endurecimento na legislação das finanças públicas, com a crise, faz florescer todo tipo de "contabilidade criativa", contornam-se as já antigas normas de execução orçamentária, avançam cada vez mais os restos a pagar, precatórios continuam sem ser pagos e os limites estabelecidos começam a virar "letra morta". Os malfeitores avançam e o Direito Financeiro não acompanha. Legislação, doutrina e jurisprudência sempre correndo atrás do prejuízo.

O orçamento é uma lei, já reconhecida pelo STF como a mais importante depois da Constituição, mas a doutrina e jurisprudência caminham com dificuldade para convencer que tem que ser cumprida tal como aprovada, sendo seu conteúdo impositivo e não autorizativo.

Os tribunais de contas se aperfeiçoam, crescem seu espaço e importância na administração pública, intensificam sua fiscalização, mas se deparam com lacunas no ordenamento, vazios doutrinários, dificuldades na interpretação das normas que regem as despesas públicas, e não conseguem conter os desvios e desperdício de recursos públicos. O Direito Financeiro precisa lhes dar o suporte necessário.

São tantos os assuntos da mais alta relevância para o país no âmbito do Direito Financeiro que o espaço desta coluna seria absolutamente insuficiente para apresentar uma enumeração que fosse uma amostra minimamente representativa de todos os temas possíveis. Vários deles foram abordados nessa coluna ao longo dos anos, mas estão a exigir estudos com maior profundidade. ${ }^{2}$

Somente por isso paro por aqui e passo a destacar aquele que é seguramente o mais relevante e inexplorado de todos: a divida pública.

Começa por não se saber, por incrível que pareça, no que consiste exatamente a "dívida pública". Um conceito ainda por ser construído, repleto de lacunas, penumbras e zonas cinzentas, pois o que se encontra é uma diversidade e complexidade nas múltiplas definições. Na literatura de finanças públicas, vemos expressões como "resultado nominal, operacional e primário", calculado "acima da linha" ou "abaixo da linha", dívida contratual, dívida mobiliária, dívida consolidada, dívida

1 Nesse sentido, destaco a obra Direito da infraestrutura: perspectiva pública, de André Castro Carvalho (São Paulo: Quartier Latin, 2014). A obra resultada da tese de doutorado Infraestrutura sob uma perspectiva pública: instrumentos para o seu desenvolvimento, defendida na Faculdade de Direito da USP em 2013, e vencedora do Prêmio Capes de Tese 2014 - melhor tese de doutorado em Direito.

2 Parte delas (2012 a 2017) compiladas neste livro. 
flutuante, operações de crédito, empréstimos públicos, crédito público, amortização, rolagem etc. E uma verdadeira "sopa de letras" que desafia aqueles que queiram compreender adequadamente o tema: NFSP (Necessidades de Financiamento do Setor Público), DBGG (Dívida Bruta do Governo Geral), DLGG (Dívida Líquida do Governo Geral), DLSP (Dívida Líquida do Setor Público), DFP (Dívida Pública Federal), DPMFi (Dívida Pública Mobiliária Federal interna e externa DPFe), DFL (Dívida Fiscal Líquida), e outras que devem ter sido esquecidas. ${ }^{3}$

O próprio conceito de operação de crédito é controvertido, quando, por exemplo, refletimos sobre o diferimento do pagamento de obrigações assumidas pelo Estado previsto nos regimes de precatórios ${ }^{4}$ e de restos a pagar. ${ }^{5}$ Se desejamos impor limites quantitativos ou qualitativos ao endividamento, é necessário delimitar a amplitude do conceito de dívida.

Não é fácil estudar um assunto e seus desdobramentos sem que se consiga saber com alguma precisão qual o seu conceito. Um desafio que precisa ser vencido, pois os gravíssimos problemas com a dívida pública estão aí, consumindo vorazmente os recursos públicos e produzindo seus efeitos mais nefastos, impedindo que o Poder Público tenha dinheiro para atender as mais básicas necessidades da população.

Para a adequada aplicação das normas de direito financeiro, é preciso dominar este caleidoscópio de conceitos para, então, compreender de que dívida estamos falando, como, quando e quanto se deseja limitar seu montante.

Falando em montante, apenas para que se tenha uma ideia, em 2015, a despesa com investimentos e inversões financeiras da União foi de $\mathrm{R}$ \$ 80,4 bilhões e $\mathrm{R}$ \$ 95,6 bilhōes, ${ }^{6}$ respectivamente. Por seu turno, as receitas com operações de crédito foram de $\mathrm{R}$ \$ 1,18 trilhão. Para onde foi a maior parte dos recursos obtidos via endividamento? O que foi feito com todo esse dinheiro? Para quem foi pago? Questôes

3 Uma sistematização desses conceitos pode ser encontrada em SILVA, Aline Dieguez B. de Meneses; MEDEIROS, Otavio Ladeira. Conceito e estatísticas da dívida pública. In: SILVA, Anderson Caputo; CARVAlHO, Lena O.; MEDEIROS, Otávio L. (Org.). Dívida pública: a experiência brasileira. Brasília: Secretaria do Tesouro Nacional/Banco Mundial, 2009. p. 101-128.

4 Sobre os precatórios, veja texto No samba dos precatórios, quem dança são os credores, nesta edição, p. 417-422.

5 Sobre restos a pagar, confira $O$ final de ano, as dividas e os "restos a pagar", nesta edição, p. 215218.

6 Dados obtidos via SIGA Brasil, sistema de acompanhamento do orçamento público mantido pelo Senado Federal. Disponível em: <https://www12.senado.leg.br/orcamento/sigabrasil>. 
difíceis de responder, principalmente em se tratando de dívida essencialmente mobiliária, decorrente da emissão de títulos públicos. ${ }^{7}$

Em se tratando de dívida pública, o que mais se encontra são perguntas, e o que menos se acha são respostas. De acordo com relatório divulgado recentemente pela Secretaria do Tesouro Nacional, ${ }^{8}$ o estoque da dívida pública federal em agosto de 2017 era de R\$3,341 trilhôes, a um custo médio de 10,62\% ao ano.

Um valor estratosférico causado em boa parte pelos nossos juros, que são considerados um dos mais altos do mundo 9 , sem que os estudiosos saibam explicar satisfatoriamente a razão desse fenômeno. ${ }^{10}$

A Constituição consagra a "regra de ouro" das finanças públicas, positivada no art. 167, III. Uma vedação ao Estado se endividar para pagar despesas de custeio. Mas não é essa a redação da norma. O limite para o endividamento público em dado exercício é o total de despesas de capital: "Art. 167. São vedados: III - a realização de operações de créditos que excedam o montante das despesas de capital, ressalvadas as autorizadas mediante créditos suplementares ou especiais com finalidade precisa, aprovados pelo Poder Legislativo por maioria absoluta". Remete o complexo cálculo dos limites ao conceito de despesas de capital, ${ }^{11}$ o que não é

7 Cujo regramento, por sinal, é bastante frágil, com normas emitidas por órgãos como o Banco Central, Secretaria do Tesouro Nacional e outros, sem passar pelo crivo do Congresso Nacional.

8 A Dívida Pública Federal se desdobra em Dívida Mobiliária Federal Interna e Dívida Pública Federal Externa. Esta última representou em agosto apenas 3,45\% da Dívida Pública Federal. Em nota publicada pelo Ministério da Fazenda, pode ser encontrado um resumo das informações e um link para download do relatório elaborado pela STN: <http://www.fazenda.gov.br/ noticias/2017/setembro/estoque-da-divida-publica-totaliza-r-3-404-trilhoes>.

9 Veja uma comparação com as taxas reais de outros países em notícia divulgada este ano no Portal $O$ Globo, com base em levantamento realizado pela Infinity Asset Management, disponível em <https://oglobo.globo.com/economia/brasil-tem-mais-alta-taxa-de-juro-entre-40-paises-21200968>. No site do FMI, é possível ter acesso a uma base de dados completa em $<$ http://data.imf.org/regular.aspx?key=61545867>. A série histórica da taxa Selic desde 1996 pode ser encontrada no site do Banco Central em <https:/www.bcb.gov.br/Pec/Copom/Port/ taxaSelic.asp>.

10 Uma boa discussão sobre o tema pode ser encontrada no estudo publicado em 2011 pelo Centro de Liderança Pública, elaborado pelos economistas Gustavo Franco, André Lara Resende, Samuel Pessoa e Márcio Nakane. Disponível em: <http://www.clp.org.br/Show/Por-que-os-juros-sao-altos-no-Brasil-?=LM1iKcl0se1SDdtw6py6wA>. Vale conferir também o ensaio publicado por Luciano Coutinho em fevereiro deste ano no Valor Econômico, disponível em <http://www.valor.com.br/opiniao/4864602/o-porque-dos-juros-altos>.

11 As definições são trazidas no art. 13 da Lei 4.320/1964 e na Portaria Interministerial STN/ SOF 163, de 4 de maio de 2001. 
simples de se delimitar, em especial nos orçamentos gigantescos da União, vários Estados e alguns Municípios.

A Lei de Responsabilidade Fiscal estabeleceu regras para a limitação da dívida pública dos entes subnacionais (arts. 29 e seguintes), e o Senado, no exercício de sua atribuição Constitucional (art. 52, V a IX), emitiu Resoluções (40 e 43, de 2001) dispondo sobre esses limites. Mas é tarefa complexa interpretar e cumprir essas normas, que exigem compreensão de contabilidade pública, e sobre as quais doutrina e jurisprudência pouco falam. Campo aberto para a "criatividade contábil" atuar com desenvoltura.

E a União, até o momento, sem limites para a sua dívida. O Projeto de Resolução do Senado (PRS) 84/2007, de relatoria do Senador José Serra, que estabelece limite para a dívida consolidada da União, tramita, tramita, mas não se converte em lei. E poucos estudiosos se debruçam sobre o assunto.

A dívida pública, poucos notam, é uma questão extremamente relevante sob o ponto de vista federativo. Não é fácil conciliar a autonomia federativa dos entes subnacionais com a plena gestão da respectiva dívida, ao mesmo tempo em que é preciso manter um rígido controle do endividamento e evitar descontrole das contas.

Vê-se a dificuldade que está sendo enfrentada por vários estados da federação, cujo destaque negativo é o Rio de Janeiro, ${ }^{12}$ obrigando a legislação financeira a criar regras às pressas para contornar a verdadeira falência em que se encontra e estabelecer um regime de recuperação fiscal. Uma questão difícil para os estudiosos de Direito Financeiro, Constitucional, Teoria do Estado e de Finanças Públicas, cujo enfrentamento é urgente. As soluções são necessárias "para ontem".

Por fim, um tema que desperta reflexões interessantíssimas é a relação entre dívida pública e a noção de justiça intergeracional..$^{13}$ Num encontro inusitado entre o Direito Financeiro e a filosofia do Direito, somos levados a nos questionar se devemos alguma coisa (e por que devemos) às gerações futuras e como o endividamento hoje pode ter impacto na economia do amanhã. Somos "usufrutuários" de um país que pertence, de fato, aos brasileiros do futuro? Assim, falar de dívida pública é, também, falar de sustentabilidade do Estado, no escopo do exercício da sua atividade financeira.

12 Um salve pela recuperação financeira do Rio de Janeiro!, nesta edição, p. 449-454.

13 Cf. GOSSERIES, Axel. Pensar a Justiça entre as geraçôes. Coimbra: Almedina, 2015. p. 33-80; NABAIS, José Casalta; SILVA, Suzana Tavares da. Sustentabilidade fiscal em tempos de crise. Coimbra: Almedina, 2011. p. 11-59. 
A interdisciplinaridade e a complexidade dos desafios à frente tornam o Direito Financeiro uma das áreas mais instigantes para a pesquisa jurídica. Se o Direito busca a concretização da justiça, dos direitos fundamentais e, de modo geral, do cumprimento do pacto estabelecido na Constituição da República, é preciso navegar pelos mares dos números e da contabilidade para que consigamos elaborar e aplicar as normas que terão reflexo na vida de cada um de nós.

A dívida pública não é um "deserto doutrinário” no Direito Financeiro. Muitos textos de excelente qualidade já foram e estão sendo produzidos..$^{14}$ Mas é preciso avançar muito mais.

O Direito Financeiro está devendo. Deve e não nega. É preciso acabar com essa dívida.

14 Dentre eles, destaco, por ordem cronológica: Crédito público e responsabilidade fiscal, de Sérgio Assoni Filho (Porto Alegre: Núria Fabris Editora, 2007), fruto da sua dissertação de Mestrado A contribuição da Lei de Responsabilidade Fiscal ao crédito público interno, apresentada em 2004, na USP; $O$ controle do endividamento público e a autonomia dos entes da federação, de César Augusto Seijas de Andrade (Dissertação - Mestrado em Direito Econômico e Financeiro - Faculdade de Direito da Universidade de São Paulo, São Paulo, 2012), disponível em <http://www.teses.usp.br/teses/disponiveis/2/2133/tde-06062013-141952/pt-br.php>, e Elementos Elementos jurídicos da reestruturação internacional da divida pública, de Gabriel Loretto Lochagin (Série Direito Financeiro. São Paulo: Blucher, 2017, fruto de sua tese de doutoramento defendida em 2016 na FDUSP). Disponível em: <https://www.blucher.com.br/livro/ detalhes/elementos-juridicos-da-reestruturacao-internaciona-da-divida-publica-1339>. 